\title{
Tumor biological profile of patients up to 50 years of age in an inland city of São Paulo
}

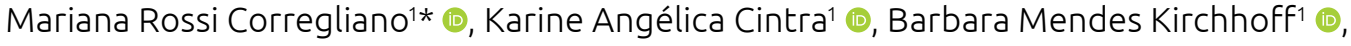 \\ Stella Souza Martins ${ }^{1}$ (), Rodrigo Tavares Silva ${ }^{1}$ (1)
}

\section{ABSTRACT}

Introduction: In Brazil, breast cancer screening is not performed in young women. However, although less frequent, the disease is generally more aggressive in this age group, with worse prognosis and refractoriness to treatment. Thus, the identification of specific subtypes by immunohistochemistry can help improve the effectiveness of treatments. Objectives: To evaluate the biological characteristics of breast tumors in patients under 50 years. Methods: This is an observational, longitudinal, retrospective study, based on data collected from medical records of the Hospital do Câncer de Franca, from January 2015 to February 2018. Results: The most frequent biological subtype was luminal B (42.5\%), and the mean age of the women was 43.6 years. The most prevalent clinical staging was IIA (31\%). Mastectomy with axillary drainage was the most used surgical treatment. A positive correlation was found between biological profiles and sociodemographic data, with a predominance of the luminal $B$ subtype in women under 40 years and luminal $A$ in those between 41 and 50 years. The mean tumor size was $4.2 \mathrm{~cm}$, being larger in older and white patients. In multiparous women, the subtypes HER2 and luminal A and B stood out. Conclusion: Luminal B and luminal A biological profiles, as well as staging II and III, were the most prevalent. Mastectomy and axillary drainage were the most common surgical treatments. The employment of these procedures should be reviewed by the service in order to improve the quality of life of the patients treated, favoring the expansion of primary conservative surgeries or post-neoadjuvant chemotherapy.

KEYWORDS: breast neoplasms; screening; immunohistochemistry.

\section{INTRODUCTION}

Currently, breast cancer is the subject of many scientific discussions about screening and treatment due to its high incidence and for being the main cause of cancer death among women in Brazil and worldwide ${ }^{1}$. The worldwide incidence is approximately 1.7 million, representing the second most common type of cancer in women ${ }^{2}$.In Brazil, according to the National Cancer Institute (Instituto Nacional de Câncer - INCA), the estimated incidence for 2020 is 66,280 new cases (61.61 cases for every 100,000 women), with the state of São Paulo having an estimated rate above the national, 81.06 cases for every 100,000 women ${ }^{2}$.

This neoplasm is more prevalent in women over 50 years of age. However, when it affects younger women, it tends to have a more aggressive clinical presentation and a worse prognosis ${ }^{3-5}$, which may be associated with factors such as late diagnosis, since they do not fit the target population of screening programs, as well as the tumor molecular characteristics.
Although breast cancer is less prevalent in young women, the likelihood of its development increases with age. The incidence of invasive breast tumors published by the Surveillance, Epidemiology, and End Results (SEER) Program between 2013 and 2017 was $1.9 \%$ for individuals aged $20-34$ years, $8.3 \%$ for $35-44$ years, and $19.7 \%$ for $45-54$ years ${ }^{6}$.

In Brazil, mammographic screening should be performed every 2 years in women aged 50 to 69 years, according to the Ministry of Health. Nonetheless, the American Cancer Society (ACS) recommends annual screening for individuals aged 45 to 54 years and biannual for those over 55 years. Women between 40 and 45 years of age are also free to have annual screenings if they so choose. In addition, ACS recommends bringing the screening forward for women at high risk of developing the disease, with mammography and breast magnetic resonance imaging (MRI) after the age of 30. This group includes women with mutations in the BRCA1 and BRCA2 genes; first-degree relatives with a known mutation in these genes; at $20 \%$ to $25 \%$ risk of developing

${ }^{1}$ Universidade de Franca - Franca (SP), Brazil.

*Corresponding author: mari_corregliano@hotmail.com

Conflict of interests: nothing to declare.

Received on: 04/30/2020. Accepted on: 07/10/2020. 
the disease, as estimated by specific models of risk calculation (BRCAPRO, Claus, BOADICEA - Breast and Ovarian Analysis of Disease Incidence and Carrier Estimation Algorithm, and TyrerCuzick); those with genetic diseases (Li-Fraumeni, Cowden, and others); or who had chest wall irradiation before the age of $30^{7}$.

The psychosocial issue is one of the most relevant after diagnostic confirmation in young patients, involving specific problems related to the preservation of fertility, pregnancy, and lactation, in addition to body image and sexuality. For this reason, these cases deserve a differential and individualized approach before the start of any therapeutic decision, since they can have long-term consequences, such as infertility and psychological disorders, such as anxiety and depression. This approach should be continuously discussed throughout the medical follow-up, in a multidisciplinary way ${ }^{4,8,9}$.

Among the risk factors for disease recurrence directly related to prognosis, the following stand out: tumor size, lymph node involvement, proximity to surgical margins after resection, and classification of the tumor molecular subtype ${ }^{3}$. The immunohistochemical evaluation can identify four different groups of tumors related to the expression of estrogen receptors, progesterone receptors, and human epidermal growth factor receptor 2 (HER2). They are luminal A, luminal B, triple-negative, and HER $2^{10,11}$.

The expression of estrogen and progesterone receptors characterizes the luminal A and B subtypes, which favor endocrine treatment, in general, and have a more favorable prognosis. The expression of epidermal growth factor receptor 2 may be present in the luminal B subtype and is the main characteristic of the HER2 subtype, which does not show hormone receptor expression, leading to greater biological aggressiveness. Triple-negative tumors do not express hormone receptors and epidermal receptor 2 . The "baseline-like" type has an overexpression of cytokeratins (CK5, CK6, and CK14) and epidermal growth factor receptor $(\mathrm{EGFR})^{12}$.

The prevalence of each subtype varies according to age, ethnicity, and behavioral aspects. Biological behavior in young women tends to be more aggressive, with unfavorable clinical evolution, greater local recurrence and distance from the disease, in addition to being associated with several genomic instabilities related to molecular subtypes, especially triple-negative, basaloid, and HER $2+^{13}$.

Thus, besides determining the classic prognostic and predictive factors, such as clinical and imaging staging to assess tumor size, lymph node involvement, and distant metastasis, the molecular classification of the disease must also be carried out in order to provide the most specific treatment for each case, seeking to control recurrences and overall disease-free survival ${ }^{13}$. Thus, this study aims to evaluate the tumor biological profiles of women aged outside the target population of mammographic screening practiced in Brazil, undergoing surgical treatment in an inland city of São Paulo.

\section{MATERIALS AND METHODS}

This is an observational, longitudinal, retrospective study, based on data collected from medical records of the Hospital do Câncer de Franca.

\section{Inclusion criteria}

Patients under 50 years of age who underwent surgical treatment at the Hospital do Câncer de Franca from January 2015 to January 2018 were included.

\section{Exclusion criteria}

Patients over 50 years of age who underwent surgical treatment and those under 50 years who were not submitted to surgical treatment were excluded.

\section{Statistical analysis}

The data obtained (demographic characteristics, initial staging, diagnostic approach, type of surgery, and adjuvant therapies) were entered into an Excel ${ }^{\circledR}$ spreadsheet and subsequently submitted to statistical analysis, represented descriptively in graphs and tables. A comparative analysis between tumor biological profiles, demographic data, and initial staging was also performed, with $\mathrm{p}<0.05$ being considered significant.

\section{Ethical aspects}

The project was submitted for consideration and approval to the Research Ethics Committee of Fundação Santa Casa de Misericórdia de Franca, following the guidelines and regulatory standards for research involving human beings established by resolution 4662012.3, and was approved under registration number 09441219.0.0000.5438.

\section{RESULTS}

The sample consisted of 34 women under 50 years of age diagnosed with breast cancer, treated at the Hospital do Câncer de Franca from January 2015 to February 2018.

The immunohistochemical analysis of the studied population revealed that the most frequent tumor subtype was luminal B (42.5\%), followed by luminal A (33.5\%), HER-2 (15\%), and, finally, triple-negative (6\%), as shown in Graph 1.

Demographic variables are described in Table 1, and the results of mammographic exams in the first appointment in Table 2.

The interval between the first appointment and the surgical treatment was 101 \pm 79.5 days (standard deviation $-\mathrm{SD}$ ). Graph 2 represents the complementary diagnostic tests performed in these patients in the service during this period. Those who only had a mammogram underwent a previous biopsy in another service; therefore, all patients submitted to surgery had a prior histopathological investigation.

Graph 3 presents the distribution of cases according to clinical staging. 


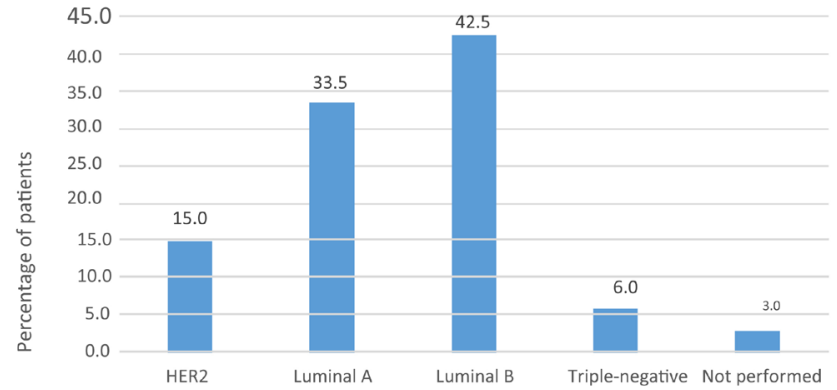

Graph 1. Percentage of patients according to tumor subtype.

Table 1. Epidemiological characteristics.

\begin{tabular}{|c|c|c|}
\hline \multirow{3}{*}{ Age (years) } & Minimum & 28 \\
\hline & Median & 45 \\
\hline & Maximum & 50 \\
\hline \multirow{3}{*}{ Ethnicity (\%) } & White & 79 \\
\hline & Multiracial & 15 \\
\hline & Black & 6 \\
\hline \multirow{4}{*}{ Marital status (\%) } & Married & 73 \\
\hline & Single & 9 \\
\hline & Divorced & 15 \\
\hline & Widow & 3 \\
\hline \multirow{4}{*}{ Parity (\%) } & Nulliparous & 3 \\
\hline & Multiparous & 54.5 \\
\hline & Primiparous & 9 \\
\hline & Not informed & 33.5 \\
\hline \multirow{4}{*}{ Origin (\%) } & State of São Paulo & 27.5 \\
\hline & Franca & 39.5 \\
\hline & State of Minas Gerais & 15 \\
\hline & Other states & 18 \\
\hline
\end{tabular}

Table 2. Mammographic BI-RADS in the first appointment. Mammographic results in the first appointment (\%)

\begin{tabular}{l|c} 
Bl-RADS $^{\oplus} 0$ & 6 \\
\hline Bl-RADS $^{\oplus} 1$ and 2 & 6 \\
\hline Bl-RADS $^{\oplus} 3$ & 6 \\
\hline Bl-RADS $^{\oplus} 4$ & 24.5 \\
\hline Bl-RADS $^{\oplus} 5$ & 15 \\
\hline Bl-RADS $^{\oplus} 6$ & 6 \\
\hline No data in the medical record or no previous exam & 36.5 \\
\hline
\end{tabular}

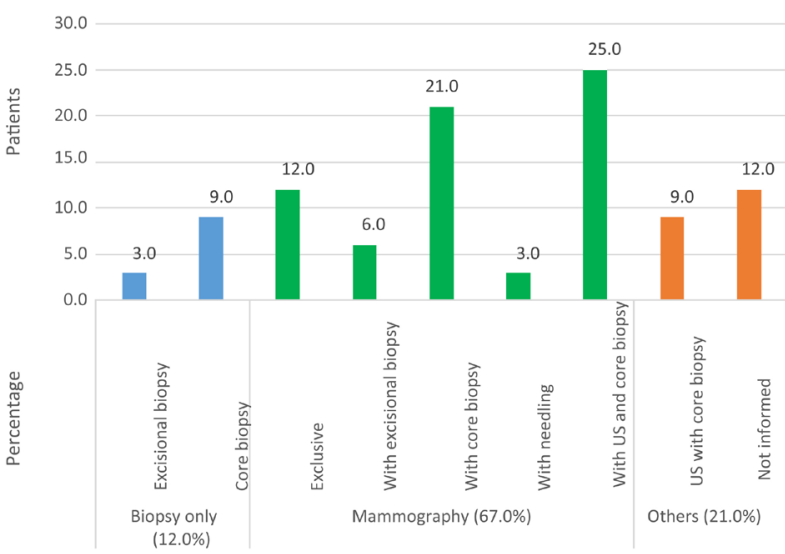

US: ultrasound.

Graph 2. Complementary diagnostic tests performed (\%).

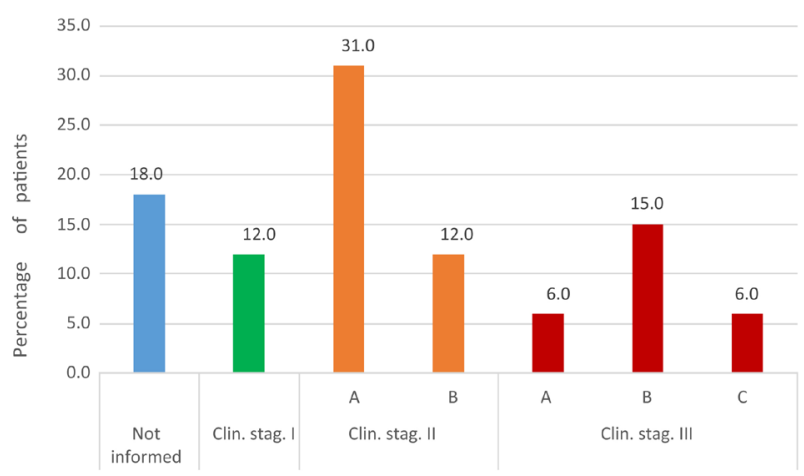

Clin. stag.: Clinical staging.

Graph 3. Clinical staging of patients (\%).

After the histological diagnosis, the immediate procedures adopted were surgery (57.5\% of cases), neoadjuvant chemotherapy (CT) (39.5\%), and adjuvant CT (3\%). Among the patients whose treatment was surgical, $73 \%$ were submitted to radical mastectomy and $27 \%$ to conservative procedures. Regarding the axillary approach, drainage was performed in $67 \%$ of women and sentinel lymph node biopsy in $18 \%$. In $3 \%$ of them, there was no research on the lymph node chain, and in $12 \%$, this information was not in the medical records. The high rate of mastectomy may be associated with the high percentage of locally advanced tumors ( $\geq$ IIB), the unfavorable relationship between tumor size and breast volume at the initial physical examination, and/or the option made by the patient, even after specialized guidance on the safety of conservative surgeries, which may also justify the low number of referrals for conservative procedures after neoadjuvant CT.

Despite the small sample size, multivariate analysis was performed between tumor characteristics and demographic data (age and ethnicity), as well as between tumor biological profiles and demographic data of the studied group. 
Table 3. Relationship of biological subtypes with age group.

\begin{tabular}{|c|c|c|c|c|c|c|}
\hline \multirow{2}{*}{$\begin{array}{l}\text { Age } \\
\text { group } \\
\text { (years) }\end{array}$} & \multicolumn{5}{|c|}{ Biological subtype (n) } & \multirow{2}{*}{ Total } \\
\hline & Luminal A & Luminal B & HER2 & Triple & Others & \\
\hline$\leq 40$ & 0 & 6 & 1 & 0 & 1 & 8 \\
\hline $41-50$ & 11 & 7 & 4 & 2 & 1 & 25 \\
\hline Total & 11 & 13 & 5 & 2 & 2 & 33 \\
\hline
\end{tabular}

The mean tumor size was $4.2 \pm 2.8 \mathrm{~cm}$ (SD). A positive relationship was found between this variable and age $(r=0.4 ; p=0.034)$, that is, the older the woman, the larger the tumor. The same happened with ethnicity - the tumor size was larger in white women compared to multiracial and black women ( $\mathrm{r}=0.6 ; \mathrm{p}=0.004)$.

No significant association was detected between biological profiles and ethnicity $\left(\chi^{2}=1.83 ; \mathrm{p}=0.40\right)$ or origin $\left(\chi^{2}=1.40 ; \mathrm{p}=0.706\right)$. However, a positive relationship was identified with parity, namely, the prevalence of HER2, luminal A, and luminal B tumors was higher in multiparous women $\left(\chi^{2}=11.67 ; p=0.009\right)$, and also with age $\left(\chi^{2}=9.49 ; p=0.08\right)$, as shown in Table 3 . The luminal A subtype was predominant in the age group 41 to 50 years $(\mathrm{p}<0.02)$. No statistical significance was found in the number of triple-negative cases among patients under 40 years of age.

\section{DISCUSSION}

The investigation of molecular subtypes in this sample demonstrated the predominance of luminal B (42.5\%), followed by luminal A (33.5\%). In a recent population study in the US, DeSantis et al. revealed that the number of triple-negative cases decreased by $1.5 \%$ to $2.6 \%$ in all ethnic groups and age groups in the period studied. The reason is unclear but may be related to the change in risk factors associated with different hormonal subtypes, such as parity, which has been decreasing in developed countries and is connected with triple-negative subtypes ${ }^{13}$. Conversely, in our multivariate analysis, multiparous women presented higher rates of tumors with receptor expression, which may be associated with the low sample size or the fact that they belong to a greater age range within this subgroup. The results of this study are compatible with the national survey carried out in 2014 by Carvalho et al., with more than 5,500 breast tumor samples from the 5 geographic regions. In the survey, they addressed the regional differences in the presentation of molecular subtypes of breast cancer, reporting a higher prevalence of luminal A and B subtypes in the Southeast and South regions of Brazil, even when analyzing age subgroups divided into older and younger than 50 years. They also found that the prevalence of triple-negative tumors was higher in the Northern region of the country. This difference in distribution can be explained by the diversity and heterogeneity of ethnic groups, eating habits, urbanization, climate, and access to health systems in Brazill ${ }^{14}$.
The prevalence data on the subtypes that express hormone receptors in this age group are also corroborated by the study by Olivieri et al., who analyzed histological samples from pre-menopausal Latin patients, using partial data from the PRECAMAMA study $^{15}$, and also identified a higher incidence of the luminal A subtype (58\%), followed by triple-negative (21\%), luminal B (11\%), and HER2 (5\%). Despite the similarity of the subtypes found in the post-menopausal period, they detected a greater expression of Ki-67, even in the luminal A subtype, and specific gene mutations in oncogenes, as in the TP53 gene, which could explain the differences in prognosis of these age groups ${ }^{16}$.

Regarding ethnicity, Clarke et al. analyzed the distribution of breast cancer subtypes in more than 90,000 patients in California and reported that black women had higher triple-negative rates at all ages ${ }^{17}$. This study found no significant differences between subtype distribution and ethnicity, which may be associated with the sample size and the ethnic diversity of our population.

We identified a low rate of patients in clinical staging I (12\%) and $70 \%$ in staging II and III, with $39 \%$ being locally advanced (above IIB). We also observed that medical records lacked this information in $18 \%$ of cases, which will be used as a warning for the professionals responsible. Among the possible explanations, we highlight the failure to perform routine mammography in patients under 50 years of age. In this age group, mammographic screening is not recommended by the Brazilian Ministry of Health national guidelines. In a recent systematic review of the cost-effectiveness of breast screening programs, Mandrik et al. showed evidence of the benefits of screening individuals aged 50 to 69 years. However, before 50 and after 70 years, other factors should be considered, such as population characteristics of disease incidence and organizational structure of health systems ${ }^{18}$. In addition, European clinical trials on the subject also question the real effectiveness of screening in this age group in decreasing mortality from the disease, given the lower sensitivity and specificity and the higher proportion of false-positive results and biopsies performed unnecessarily ${ }^{19}$.

In 2013, a national study carried out with more than 12,000 breast cancer patients under 40 years of age (mean age 36 years) also found a higher prevalence of IIA staging ${ }^{1}$. Similar data were presented by Stival et al., who detected a higher frequency of IIA and IIB tumors in patients aged between 40 and 50 years, with no significant differences in individuals over 50 years $^{20}$.

The time between visiting the service and surgical treatment was longer than that recommended by the Ministry of Health ( 60 days $)^{21}$ and may be associated with the disproportion between the demand for care and the organizational structure of the service.

Concerning surgical treatment, some services still tend to perform a greater number of radical surgeries (mastectomies) in younger patients to the detriment of conservative procedures, as observed in this study, in which only $27 \%$ of patients were 
submitted to conservative treatments. Moreover, the rate of patients referred to neoadjuvant CT was relatively low (39.5\%), and these individuals are potential candidates for conservative surgery later. This finding can be explained by particular decisions between the staff physicians and their patients or by the lack of closer integration between the clinical oncology, mastology, and plastic surgery teams. No data were collected on the breast reconstructions performed, which, due to the structuring of the teams, are usually done late, in the second surgical period. Both conservative surgery and mastectomy are well-established local treatments for invasive breast carcinomas, and several randomized clinical trials with a follow-up of more than 20 years have shown that conservative surgery is safe and has outcomes equivalent to mastectomy as to overall disease-free survival in stages I and $\mathrm{II}^{22}$. In 2010, Veronesi et al. revealed that the cumulative risks of local recurrence after conservative surgery followed by radiotherapy would be acceptable in ten years (12\%), and, therefore, age should not be a determining factor for surgical recommendation, which should be based on the oncological safety defined by the tumor/breast ratio and a favorable cosmetic result ${ }^{23}$. In more recent studies, the recurrence after conservative surgery and subsequent adjuvant treatment decreased to $5.2 \%$ and $8.7 \%$, according to protocols of the National Surgical Adjuvant Breast and Bowel Project (NSABP), in tumors without and with axillary involvement, respectively ${ }^{24,25}$. In addition, several studies report that the recurrence rate is associated with different molecular subtypes, being higher in triple-negative tumors and those with overexpression of HER2 ${ }^{22}$. We emphasize the importance of performing an appropriate preoperative screening with imaging tests (especially mammography and breast ultrasound, as well as MRI when necessary) to rule out multicentric tumors, which would make conservative procedures contraindicated ${ }^{25}$.

Thus, the immunohistochemical profile of this group of patients and the initial staging were similar to those of older age groups, according to the literature review. This finding also points to a worse prognosis of the disease at younger ages, possibly associated with complex factors of tumor genetic instability, whose knowledge is in progressive construction and will increasingly expand the individualization of therapeutic possibilities.

\section{CONCLUSION}

The most prevalent biological profiles in this sample of patients aged under 50 years were luminal B and luminal A subtypes and staging II and III. Mastectomy and axillary drainage were the most common surgical treatments. The employment of these procedures should be reviewed and rethought by the service in order to improve the quality of life of the patients treated, favoring the expansion of primary conservative surgeries or post-neoadjuvant chemotherapy.

\section{AUTHORS' CONTRIBUTIONS}

M.R.C.: data curation, formal analysis, investigation, writing original draft; K.A.C.: conceptualization, investigation, methodology, investigation, project administration, supervision, validation, visualization, writing - review \& editing; B.M.K.: data curation, formal analysis, investigation, writing - original draft; S.S.M.: data curation, formal analysis, investigation, writing - original draft; R.T.S.: methodology, validation, writing - review \& editing.

\section{REFERENCES}

1. Pinheiro AB, Lauter DS, Medeiros GC, Cardozo IR, Menezes LM, Souza RMB, et. al. Câncer de mama em mulheres jovens: análise de 12.689 casos. Rev Bras Cancerol. 2013;59(3):351-9. https://doi.org/10.32635/2176-9745.RBC.2013v59n3.500

2. Brazil. Ministério da Saúde. Instituto Nacional de Câncer José Alencar Gomes da Silva. Estimativa 2020: incidência de câncer no Brasil [internet]. Rio de Janeiro: Inca; 2019. 120 p. [Accessed on Nov 11, 2020]. Available at: https://www.inca.gov.br/sites/ ufu.sti.inca.local/files/media/document/estimativa-2020incidencia-de-cancer-no-brasil.pdf

3. Cancello G, Maisonneuve P, Rotmensz N, Viale G, Mastropasqua MG, Pruneri G, et al. Prognosis and adjuvant treatment effects in selected breast cancer subtypes of very young women ( $<35$ years) with operable breast cancer. Ann Oncol. 2010;21(10):1974-81. https://doi.org/10.1093/annonc/ mdq072

4. Abdel-Razeq H, Almasri H, Abdel Rahman F, Abdulelah H, Abu Nasser M, Salam M, et al. Clinicopathological characteristics and treatment outcomes of breast cancer among adolescents and young adults in a developing country. Cancer Manag Res. 2019;11:9891-7. https://doi.org/10.2147/CMAR.S229337

5. Tang LC, Jin X, Yang HY, He M, Chang H, Shao ZM, et al.Luminal B subtype: a key factor for the worse prognosis of young breast cancer patients in China. BMC Cancer. 2015;15:201. https://doi. org/10.1186/s12885-015-1207-z

6. National cancer institute. Surveillance, epidemiology and end results program. Cancer stat facts: female breast cancer [internet]. [Accessed on Nov. 11, 2020]. Available at: https:// seer.cancer.gov/statfacts/html/breast.html

7. Smith RA, Andrews KS, Brooks D, Fedewa SA, ManassaramBaptiste D, Saslow D, et al. Cancer screening in the united states, 2019: a review of current American cancer society guidelines and current issues in cancer screening. CA Cancer J Clin. 2019;69(3):184-210. https://doi.org/10.3322/caac.21557.

8. Partridge AH, Pagani O, Abulkhair O, Aebi S, Amant F, Azim $\mathrm{HA}$ Jr, et al. First international consensus guidelines for breast cancer in young women (BCY1). Breast. 2014;23(3):209-20. https://doi.org/10.1016/j.breast.2014.03.011 
9. Bártolo A, Santos IM, Valério E, Monteiro S. Depression and healthrelated quality of life among young adult breast cancer patients: the mediating role of reproductive concerns. J Adolesc Young Adult Oncol. 2020;9(3):431-435. https://doi.org/10.1089/jayao.2019.0144

10. Elias S, Facina G, Araujo Neto JT. Mastologia: condutas atuais. 1st ed. Nazário ACP, editor. São Paulo: Manole; 2015.

11. Alves HFBES; Viapiana PS; Silva KLT. Aspectos clínicos e patológicos do câncer de mama em mulheres jovens atendidas na FCecon entre 2003 e 2013. Rev Bras Cancerol. 2017;63(2):1039. https://doi.org/10.32635/2176-9745.RBC.2017v63n2.145

12. Dent R, Hanna WM, Trudeau M, Rawlinson E, Sun P, Narod SA. Time to disease recurrence in basal-type breast cancers: effects of tumor size and lymph node status. Cancer. 2009;115(21):4917-23. https://doi.org/10.1002/cncr.24573

13. DeSantis CE, Ma J, Gaudet MM, Newman LA, Miller KD, Goding Sauer A, Jemal A, et al. Breast cancer statistics, 2019. CA Cancer J Clin. 2019;69(6):438-51. https://doi.org/10.3322/caac.21583

14. Carvalho FM, Bacchi LM, Pincerato KM, Van de Rijn M, Bacchi CE. Geographic differences in the distribution of molecular subtypes of breast cancer in Brazil. BMC Womens Health. 2014;14:102. https://doi.org/10.1186/1472-6874-14-102

15. Olivier M, Bouaoun L, Villar S, Robitaille A, Cahais V, Heguy A, et. al. Molecular features of premenopausal breast cancers in Latin American women: pilot results from the PRECAMA study. PLoS One. 2019;14(1):e0210372. https://doi.org/10.1371/ journal.pone.0210372

16. Romieu I, Biessy C, Carayol M, His M, Torres-Mejía G, Ángeles-Llerenas A, et al. Reproductive factors and molecular subtypes of breast cancer among premenopausal women in Latin America: the PRECAMA study. Sci Rep. 2018;8(1):13109. https://doi.org/10.1038/s41598-018-31393-7

17. Clarke CA, Keegan TH, Yang J, Press DJ, Kurian AW, Patel $\mathrm{AH}$, et al. Age-specific incidence of breast cancer subtypes: understanding the black-white crossover. J Natl Cancer Inst. 2012;104(14):1094-101. https://doi.org/10.1093/jnci/djs264

18. Mandrik O, Ekwunife OI, Meheus F, Severens JLH, Lhachimi S, Uyl-de Groot CA, et al. Systematic reviews as a "lens of evidence": determinants of cost-effectiveness of breast cancer screening. Cancer Med. 2019;8(18):7846-58. https://doi. org/10.1002/cam4.2498

19. Cardoso F, Loibl S, Pagani O, Graziottin A, Panizza P, Martincich L, et al. The European society of breast cancer specialists recommendations for the management of young women with breast cancer. Eur J Cancer. 2012 Dec;48(18):335577. https://doi.org/10.1016/j.ejca.2012.10.004

20. Stival RSM, Prestes ALO, Mansani FP. Câncer de mama em mulheres jovens: uma análise do estadiamento clínico inicial e dos subtipos moleculares dos tumores. Rev Bras Mastologia. 2014;24(1):17-22. https://doi.org/10.5327/Z201400010004RBM

21. Brasil. Ministério da Saúde. Instituto Nacional de Câncer José Alencar Gomes da Silva. A situação do câncer de mama no Brasil: síntese de dados dos sistemas de informação[internet]. Rio de Janeiro: Inca; 2019. 85 p. [Accessed on Nov. 11, 2020]. Available at: https://www.inca.gov.br/sites/ufu.sti.inca. local/files//media/document//a_situacao_ca_mama_ brasil_2019.pdf

22. Moo TA, Sanford R, Dang C, Morrow M. Overview of breast cancer therapy. PET Clin. 2018;13(3):339-54. https://doi. org/10.1016/j.cpet.2018.02.006

23. Gentilini O, Botteri E, Rotmensz N, Toesca A, Oliveira H, Sangalli C, et al. Breast-conserving surgery in 201 very young patients (<35 years). Breast. 2010;19(1):55-8. https://doi. org/10.1016/j.breast.2009.11.001

24. Anderson SJ, Wapnir I, Dignam JJ, Fisher B, Mamounas EP, Jeong JH, et al. Prognosis after ipsilateral breast tumor recurrence and locoregional recurrences in patients treated by breast-conserving therapy in five National Surgical Adjuvant Breast and Bowel Project protocols of node-negative breast cancer. J Clin Oncol. 2009;27(15):2466-73. https://doi. org/10.1200/JCO.2008.19.8424

25. Katipamula R, Degnim AC, Hoskin T, Boughey JC, Loprinzi C, Grant CS, et al. Trends in mastectomy rates at the Mayo Clinic Rochester: effect of surgical year and preoperative magnetic resonance imaging. J Clin Oncol. 2009;27(25):4082-8. https:// doi.org/10.1200/JCO.2008.19.4225 